\section{Aspectos da comunicação nas práticas avaliativas na Estratégia Saúde da Família}

\section{Aspects of communication in Family Health Strategy evaluation practice}

Katia Virginia de Oliveira Feliciano 1

1 Grupo de Estudos de Gestão e Avaliação em Saúde. Instituto de Medicina Integral Prof. Fernando Figueira (IMIP). Rua dos Coelhos, 300. Boa Vista. Recife, PE, Brasil. CEP: 50.070-550. E-mail:kfeliciano@terra.com.br

\begin{abstract}
This article adopts a hermeneutical and critical approach, in order to examine the importance of the conditions making possible and legitimizing communications practices aiming to evaluate the Family Health Strategy. It is the participatory nature of the strategy that enables it to establish social networks and negotiation techniques aiming to achieve coherence between the autonomous judgment of each individual and the expectation of obtaining contracts and agreements for joint projects. The shared decisionmaking process is shown to be a network of relations that are always in tension, in which the success of negotiations may be hampered by asymmetrical power relations and unfair distribution of the power to make threats. This means that is indispensable that what is said and how language is used be called into question. In order to reflect on language as a construct in a given context, the article draws on the work of Gadamer, Habermas and Ricoeur. It aims to reaffirm the importance of intersubjectivity as a condition for decision-making, thereby helping to build up the training potential of evaluation in the area of health.
\end{abstract}

Key words Communication, Participative planning, Program evaluation, Health evaluation, Evaluation

\section{Resumo}

Este artigo adota uma perspectiva hermenêutica e crítica para examinar a importância das condições de possibilidade e legitimidade de práticas comunicativas para a avaliação na Estratégia Saúde da Família. É o caráter participativo da avaliação que possibilita estabelecer redes sociais e técnicas de negociação, visando à coerência entre a autonomia do julgamento de cada um e a expectativa de obter acordos e pactos na construção de projetos comuns. O processo decisório compartilhado se apresenta como uma rede de relações sempre tensas, na qual, o êxito da negociação pode ser prejudicado pela assimetria de poder e os potenciais de ameaça injustamente distribuidos entre interlocutores, tornando indispensável o questionamento do que é dito e da própria situação de uso da linguagem. Para refletir sobre a linguagem como objeto construido, em um dado contexto, recorre-se a Gadamer, Habermas e Ricoeur. Espera-se reafirmar a importância da intersubjetividade como condição de possibilidade das decisões, contribuindo para o fortalecimento do potencial formativo da avaliação em saúde.

Palavras-chave Comunicação, Planejamento Participativo, Avaliação de Programas e Projetos de Saúde, Avaliação em saúde, Avaliação 


\section{Introdução}

A adoção da Estratégia Saúde da Família como eixo estruturante do sistema público de saúde, a enorme expansão de cobertura por meio desta estratégia e a complexidade do seu processo de implantação levaram o Ministério da Saúde, desde 2003, a fortalecer a avaliação enquanto importante instrumento para a gestão do Sistema Único de Saúde (SUS). Nesse sentido, a construção da Política Nacional de Avaliação da Atenção Básica em Saúde, desenvolvida pela Coordenação de Acompanhamento e Avaliação do Departamento de Atenção Básica (CAA/DAB) da Secretaria de Atenção à Saúde, objetivou a indução de uma cultura avaliativa nas três esferas de governo, com o apoio das instituições de ensino e pesquisa. 1

A institucionalização traz à discussão o poder transformador da avaliação em saúde, que está condicionado à participação daqueles, potencialmente, afetados pelas consequências que possam advir da sua prática. Depara-se, portanto, com a necessidade de constituir, de modo duradouro, espaços de encontro entre interlocutores (políticos, planejadores, gestores, trabalhadores de saúde, usuários e não-usuários, instituições do setor e de fora do setor saúde), nos quais se arbitre entre reivindicações concorrentes relativas aos interesses e aos valores relacionados com a saúde, a doença e o cuidado. ${ }^{2}$ Em quaisquer situações, os discursos e as práticas resultam da interação entre diversas pretensões, exigências e condições de validez.3-5

O reconhecimento do processo avaliativo como construção coletiva, por conseguinte, a assunção do caráter contextual e reconstruído das decisões sobre os modos de agir, está presente nos discursos oficiais que expressam a expectativa institucional de aceitabilidade e legitimidade da Estratégia Saúde da Família. ${ }^{6} \mathrm{Na}$ busca de efetivação da integralidade em saúde, a amplitude e a diversidade das redes de comunicação que é possível estabelecer representam desafios práticos para o campo da avaliação. Particularmente, devido à proposta de operacionalizar a promoção da saúde por intermédio dessa estratégia. ${ }^{7}$ A partir da concepção mais abrangente da Carta de Ottawa, em 1986, quando a promoção da saúde, superando as limitações das abordagens de risco, passa a dar prioridade às mediações com outros setores e à participação social. ${ }^{8}$ Desse modo, ganha destaque na avaliação o sentido de fortalecimento da transformação em prol da cidadania e dos direitos humanos.

Na polissemia dos conceitos por meio dos quais se busca esclarecer o que significa avaliar, manifesta-se cada vez mais a ideia de compartilhamento da responsabilidade e compromisso na tomada de decisões e encaminhamentos das mesmas. ${ }^{9-12}$ Amplia-se o debate sobre as posturas epistemológicas e metodológicas potencialmente mais adequadas para a avaliação de programas e serviços de saúde, com a negociação entre atores representando o cerne da proposta de avaliação de quarta geração desenvolvida por Guba e Lincoln. ${ }^{13}$ Nessa, a mensuração de resultados da intervenção (primeira geração), descrição das atividades desenvolvidas (segunda geração) e julgamento da adequação segundo referenciais técnicos (terceira geração), passa pela construção de pactos efetivados mediante a linguagem, por sujeitos que buscam o ajuste entre práticas e ideais de vida.

A linguagem é um elemento estruturador da experiência, sendo sempre utilizada em um dado contexto sociocultural condicionado por convenções que regulam a interação humana.3,4,14 Uma maior perspicácia relacionada ao uso comum da linguagem trará uma visão mais aguçada das posições e funções de indivíduos e coletividades, jogando um pouco de luz sobre o obscuro e o contraditório presente na realidade que por meio da prática avaliativa se pretende transformar. Também propiciará uma visão mais sutil dos níveis diferenciados de poder que afetam a possibilidade de desenvolvimento de competências para participar da vida em sociedade. $14 \mathrm{O}$ modo de utilização da linguagem pode trazer um sério problema para a constituição do processo avaliativo como um dispositivo de mudança.

Neste artigo, adota-se uma perspectiva hermenêutica e crítica para examinar a importância das condições de possibilidade e legitimidade de práticas comunicativas para a avaliação no âmbito da Estratégia Saúde da Família. Na reflexão sobre a linguagem como objeto construído, prática concreta que se constitui em um dado contexto social e interacional, recorre-se a Gadamer, Habermas e Ricoeur para conferir visibilidade a uma esfera de interesse que não é mais técnico, o qual ressalta a eficácia de intervenções sobre o mundo, mas prático, referindose à busca de acordos e pactos sobre a melhor forma de agir. A perspectiva habermasiana também remete ao interesse pela emancipação, portanto, à participação dos indivíduos na discussão dos objetivos e meios dos processos sociais pelos quais são afetados.

\section{Comunicação e avaliação em saúde}

A comunicação é uma ferramenta imprescindível da avaliação em saúde. Todavia, em situações e 
contextos específicos, merece consideração as desigualdades de autoridades técnicas e científicas, acrescidas na relação entre os avaliadores e os avaliados da autoridade política, que têm criado obstáculos para o questionamento sobre a correção de ações e normas e a adequação de avaliações e de padrões segundo os quais se interpretam as necessidades. É justamente o entrecruzamento de linguagem e poder que mostra a importância de reinterpretar não apenas o que é dito, mas a própria distribuição dos papéis aos falantes como pré-condição para realizar a comunicação. 3,15,16 Conforme Marcondes (2000: 47) ${ }^{14}$, isso significa interrogar-se:

[...] sobre o objetivo, o propósito do ato no tipo de situação de discurso em que se realiza, explicitando os seus efeitos e conseqüências

Para Gadamer (2006: 129), 17 a autoridade, em um sentido positivo, diz respeito à superioridade do saber ou do ser-capaz-de-fazer, à superioridade da compreensão. No entanto, ele chama à atenção:

Aquele que tenta obter vantagem do peso institucional de sua superioridade e coloca isso no lugar de argumentos, sempre corre o risco de falar de forma autoritária e não autoritativa.

A legitimidade da autoridade tem a autocrítica como uma exigência ética. Também implica em reconhecer que a liberdade crítica do outro pode exigir até mesmo a limitação da própria autoridade. Aspectos que denotam o profundo entrelaçamento interno entre autoridade e liberdade crítica. Contudo, no âmbito de uma racionalidade que confere primazia à ciência e à técnica na formação da opinião e da vontade, liberdade crítica e autoridade constituem-se como opostos.

Com efeito, há oposição entre questionamento e autoridade nos contextos de ação em que a assimetria de poder está vinculada à dominação. No desenvolvimento das práticas em saúde a desvalorização do saber acumulado pela experiência prática cotidiana pode ser considerada legítima, com base nos processos de racionalização que privilegiam a um saber-fazer fundado no conhecimento técnico-científico. ${ }^{15-17}$ Também é legitimada pela universalização de interesses que se fundamenta na ideia do beneficiamento de todos pela adesão aos critérios e normas técnicas preconizados para qualificar a atenção à saúde. Esta ideia induz a uma valorização positiva da universalização, que parece estar em sintonia com o alcance do objetivo mais caro à institucionalização da avaliação: a transformação para a garantia da qualidade da atenção prestada.

A sobrevalorização dessa racionalidade, de caráter estratégico, reduz a comunicação à transmissão unilateral de informações e faz com que a linguagem seja utilizada como meio para persuadir acerca da valoração correta de possíveis alternativas de ação, aparecendo como neutra e universal. Dessa perspectiva, a decisão sobre a melhor forma de agir não pressupõe o reconhecimento do caráter simultaneamente contextual e singular dos modos de andar a vida, sendo tomada de forma fundamentalmente monológica. 3,15 Embora as relações interpessoais entre os usuários e os trabalhadores de saúde possam ser cordiais e os usuários possam até mesmo se mostrar satisfeitos com o caráter informativo da comunicação. No entanto, como aponta Habermas, 15 essa racionalidade encerra uma pretensão tecnocrática que obscurece o conflito de interesses do cotidiano que torna necessária a discussão prática.

A desconsideração pela contribuição do saber prático, adquirido pela experiência, para a decisão, segundo Gadamer, 16 converte a práxis em uma aplicação acrítica do conhecimento técnico-científico, difundindo uma perda de flexibilidade no trato com o mundo, uma renúncia à liberdade de escolha em relação ao próprio poder-atuar. Desse modo, a práxis que significa sempre escolha e decisão entre possibilidades é reduzida à exequibilidade daquilo que é preconizado fazer. Muito embora o julgamento dirigido à situação concreta, requeira a reivindicação de validade das propostas quanto à eficácia, legitimidade nos contextos de desenvolvimento e capacidade de estabelecer efetiva comunicação entre as diferentes perspectivas em interação. 3

É preciso, neste ponto, trazer a visão habermasiana de uso da linguagem na busca de alcançar o entendimento, no sentido de um processo de interpretação cooperativo sobre projetos comuns de vida, para encontrar respostas para a pergunta: "o que desejo/desejamos fazer?". Nesta indagação não se preserva a ideia normativa do bom sem restrição que descontextualiza a ação, o desejo é expresso por atos de fala do tipo optativo que indicam o interesse prático de organizar as interações entre os seres humanos, levando em conta três níveis de legitimação discursiva que se traduzem nas capacidades de: a) desenvolver ações legítimas no âmbito dos projetos sociais relativos às realidades em que se conformam estes discursos (correção normativa); b) expressar certezas que são compartilháveis (verdade proposicional); e c) estabelecer efetiva comunicação entre as diferentes perspectivas subjetivas em interação (autenticidade expressiva).3,18 
Cabe atentar para a simultaneidade das regras que regulam os contextos de interação, até porque a ação instrumental está referida à aquisição de habilidades para a realização de atividades essenciais à vida prática, assim como em muitas circunstâncias pretende-se influenciar a decisão do outro. Para Habermas, 18 os sujeitos que atuam comunicativamente também podem se orientar para o próprio êxito, mas só alcançam o êxito almejado, mediante o entendimento. Destaca-se, então, a dimensão ética e política da ação comunicativa na qual o interesse emancipatório desempenha um papel essencial. $\mathrm{Na}$ busca de, mediante o processo de reflexão e autoreflexão, explicitar no nível da consciência o conflito das desigualdades, da resistência e da conformidade que, ocultado, negado ou obscurecido, estava condicionando as decisões. 15

Habermas 3 alerta para os contrastes nos conceitos de responsabilidade e autonomia quando se leva em conta a racionalidade da ação. $\mathrm{Na}$ ação comunicativa, como não se pode prescindir do convencimento sobre a correção dos argumentos apresentados, responsável é aquele capaz de orientar os seus atos por pretensões de validade intersubjetivamente reconhecidas. A possibilidade de olhar criticamente as propostas e de encontrar caminhos alternativos de ação é parte do exercício democrático, que implica no desenvolvimento da autonomia para assumir a responsabilidade do próprio julgamento. A autonomia pressupõe um sujeito responsável, que se reconhece capaz de agir de conformidade com a sua vontade, mas sabe que os outros são constitutivos de seu problema e de sua possível solução. Isso solicita outra atitude em relação a si mesmo e ao outro, sendo menores as possibilidades de ocorrer abuso de poder.

No agir estratégico, a responsabilidade diz respeito à escolha correta entre alternativas de ação e à capacidade de controlar algumas condições necessárias para alcançar os intentos. O que amplia a autonomia, aumentando as possibilidades daqueles que detêm maiores poderes recorrerem à coerção na negociação dos conflitos. Aqui a ideia de autonomia está ligada à do "constrangimento", pois alude a um sujeito autônomo, gestor de suas relações e necessidades, capaz de fazer valer sua vontade, exercendo o poder sobre o outro. ${ }^{3}$ Ricoeur (1991: 257) ${ }^{19}$ argumenta que a violência é fruto também da não-reciprocidade na interação, da oposição entre a forma ativa do fazer e a forma passiva do ser feito, portanto, do suportar.

É difícil imaginar situações em que as relações não sejam assimétricas. Diante dessa dissimetria Habermas 18 identifica a negociação como uma alter- nativa para solução conflitos e de formação coletiva da vontade. O êxito da negociação, contudo, pode ser prejudicado por uma assimetria de poder que esteja ligada à dominação. Por isso, para cumprir de fato o seu papel, a negociação necessita garantir a equidade dos compromissos estabelecidos, os quais regulam, entre outras coisas, o direito à participação, o tipo de temas, contribuições, informações e a permissão de sanções. Assim, a simetria dos interesses de cada participante é considerada como um problema da combinação entre os mesmos, com o pacto sendo alcançado de modo não-coercitivo, levando à formação de uma vontade geral que agrega os argumentos e as alternativas na repartição de benefícios.

São enormes os desafios para estabelecer um processo equitativo de negociação, mas esse procedimento, com todas as suas dificuldades e contradições, representa um passo essencial para assegurar o potencial formativo da avaliação. É fato que a utilidade prática da avaliação está fortemente vinculada à participação na produção de subsídios e tomada de decisões relevantes relacionadas com a qualidade de vida e assistência à saúde. 10 Este potencial formativo adquire destaque no âmbito da institucionalização da avaliação, por meio da integração do monitoramento e da investigação avaliativa à rotina dos serviços. ${ }^{1}$ O propósito de melhorar a qualidade da atenção básica no seu decorrer, com ênfase na prestada pela Estratégia Saúde da Família, reitera a importância da intersubjetividade como condição de possibilidade das decisões.

\section{Prática avaliativa como "ação sensata"}

No horizonte da integralidade do cuidado nas equipes de saúde da família, o discurso institucional inclui o controle e a regulamentação das possibilidades de trabalho, ao mesmo tempo em que dá espaço à improvisação e criatividade para enfrentar o inesperado. ${ }^{6}$ Nesse sentido, a sua adequada operacionalização não está restrita ao cumprimento das diretrizes programáticas que deveriam guiar o processo de trabalho, já que se propõe a assimilar as necessidades de saúde que emergem no contexto local. Desse modo, trazendo à luz modos de pensar, de sentir, de agir e interagir não considerados na organização anteriormente dada. ${ }^{20}$ Difunde-se uma nova expectativa sobre o que cerca o cotidiano da equipe, pois, em um processo de trabalho a ser constituído como práxis, é essencial o reconhecimento de que toda tomada de posição envolve uma possibilidade de contraposição.

Aqui, em princípio, esferas cada vez mais 
amplas da vida humana precisam ser contempladas no âmbito de práticas que, expressando a responsabilidade sanitária, visam o desenvolvimento de habilidades pessoais e institucionais para a proteção da saúde e o estabelecimento de parcerias com o conjunto de práticas sociais comprometidas com a qualidade de vida (articulação dos recursos comunitários e de outros setores). ${ }^{6}$ A possibilidade de um contato compreensivo com os participantes traz consigo a exigência de, no contexto de cada situação, reconhecer o caso de aplicação de uma regra geral. ${ }^{16,17} \mathrm{Na}$ organização e no processo de trabalho em saúde a tarefa é unir o saber-fazer tecnológico à capacidade de considerar visões de mundo e formas de ação alternativas.

A intersubjetividade das práticas em saúde envolve necessariamente o diálogo para que se possa verbalizar e resolver conflitos.3,15 $\mathrm{Na}$ equipe de saúde da família, os novos padrões de autonomia e responsabilidade profissional, que sustentam a transformação na dinâmica social das práticas em saúde, requerem, de um lado, o questionamento das desigualdades estabelecidas entre os distintos trabalhos e a aceitação da interdependência da autonomia profissional. De outro, a formulação de um projeto comum fundado na interdisciplinaridade do conhecimento e no caráter multiprofissional da operação do trabalho. Também implica em negociação na busca de construir projetos terapêuticos individuais e estabelecer pactos entre a equipe e a comunidade, a equipe e a rede integrada de serviços de saúde, bem como entre a equipe e as distintas instâncias institucionais de dentro e de fora do setor saúde. 2

Dessa perspectiva, a tomada de decisões relacionadas com a organização do processo de trabalho, as práticas em saúde, a coordenação de ações, o planejamento e a avaliação está apoiada na coerência entre a autonomia do julgamento de cada um e a expectativa de obter acordos e pactos na construção, entre outros aspectos, de projetos terapêuticos individualizados e de projetos de intervenção coletivos Assim, o processo avaliativo em saúde remete de maneira simultânea à ideia de necessidade e de alguma incerteza quanto a seu destino, tendo em vista o condicionamento recíproco entre conhecimento, compreensão, execução e transformação da realidade.

Potvin, citada por Bodstein, ${ }^{11}$ considera esta indeterminação, chamando a atenção para o programa (formulação de objetivos e estratégias para alcançar a transformação visada pelo projeto) como sistema de ação em que, apesar da possibilidade de definição de seus elementos básicos como o contexto de desenvolvimento, a estrutura, o processo de trabalho e os efeitos que podem ser atribuídos às ações realizadas, não deveriam ser reduzidos à racionalidade linear de um modelo lógico. Note-se que, mesmo quando a proposta de intervenção é pactuada, o desenvolvimento das ações pode não corresponder ao que foi concebido, além disso, as mudanças não se referem apenas aos resultados e efeitos programados.

Essa indeterminação ressalta o caráter ético das práticas em saúde que não permite restringir a sua avaliação aos julgamentos da adequação das atividades executadas, com base na aplicação de regras técnicas e estratégicas descontextualizadas. Não obstante, como lembra Ayres, ${ }^{21}$ nas práticas avaliativas os aspectos técnicos e científicos necessitam de entrar em contato com os não-técnicos, para que os pressupostos, métodos e resultados das tecnociências da saúde possam dialogar com os inalienáveis interesses de compreensão e simultânea construção do si mesmo e do outro. É a aceitação deste sentido formativo - o conceito gadameriano de formação refere-se à maneira humana de aperfeiçoar aptidões e faculdades - que possibilita a configuração de um saber prático que cria o hábito de recorrer ao bom senso na tomada de decisões.

$\mathrm{Na}$ medida em que estabelece uma relação consciente e negociada na formulação e avaliação continuada de um projeto comum, a prática avaliativa se legitima pela capacidade de julgar e emitir juízos, constituindo-se como práxis. Assim posta, como práxis, a avaliação estará de fato implicada com o que almeja em sua última instância: a transformação da realidade. $\mathrm{O}$ movimento recursivo entre o ter-sido, o está-sendo e o vir-a-ser, em um processo incessante de retificação das escolhas iniciais, tornando factível a ideia de aprimoramento das políticas de saúde, da gestão dos serviços, da formação e supervisão técnica e ética dos profissionais, com o propósito de oferecer adequada atenção, melhor condição de saúde e qualidade de vida. Também factível a ideia de modificação contínua dos envolvidos, a partir da experiência em que estão engajados.

A práxis avaliativa, desse modo, identifica-se com o trabalho incessante de interpretação fundado, segundo Ricoeur, ${ }^{19}$ na complementaridade entre os componentes individuais, interpessoais e coletivos de uma perspectiva ética que pressupõe o desenvolvimento por indivíduos e coletividades de competências para participar da vida em sociedade. Dos envolvidos na rede de negociações são requeridas habilidades comunicativas e uma capacidade de reflexão que qualifique a mediação de 
compromissos sobre a melhor forma de agir. Esse ponto de vista também elucida a relação recorrente entre as questões de saúde e os projetos de vida.

Os procedimentos participativos resgatam o respeito pelas distintas esferas da experiência, permitindo que seja vivenciado um permanente processo de aprendizado e autocorreção, no qual a argumentação desempenha um papel importante.9,12 É o caráter participativo da avaliação que possibilita estabelecer redes sociais e técnicas de negociação, nas quais o outro se constitui como mediador na relação com o mundo, assumindo o compromisso e a responsabilidade no julgamento sobre questões como: O que queremos por meio dessas escolhas? Como fazer com que a escolha coletiva seja verdadeiramente a escolha de cada um, a escolha de todos? No âmbito da decisão individual ou coletiva, quando está em jogo a tomada de posição diante de pretensões de validade, controversas, sobre a melhor forma de atuar, Habermas (2004: 14)22 chama a atenção para a ética que perpassa a força consensual do argumento:

\footnotetext{
O que pesa sobre as decisões dos participantes de um discurso prático é a força de obrigatoriedade daquela espécie de razões que, em tese, podem convencer a todos igualmente - não só as razões que refletem minhas preferências, ou as de qualquer outra pessoa, mas as razões à luz das quais todos os participantes podem descobrir juntos, dado um assunto que precisa ser regulamentado, qual a prática que pode atender ao interesse de todos.
}

O conjunto das medidas tomadas pelos indivíduos e instituições para preservar ou restaurar a intersubjetividade da decisão tem adquirido importância, no Brasil, desde os meados dos anos 1990. Época a partir da qual se tornaram mais comuns as propostas e práticas de avaliação que consideram a inclusão de julgamentos diferentes originários dos distintos pontos de vista dos implicados com um programa ou serviço. Como mostram Bodstein, 11 Furtado, 12 Campos, 23 Bursztyn e Ribeiro, ${ }^{24}$ aspecto cada vez mais valorizado é o caráter reflexivo e socializado dos procedimentos participativos que desencadeiam um processo de aprendizagem social e organizacional. Entretanto, as abordagens construtivistas e participativas têm sido efetivamente utilizadas na avaliação de projetos de promoção em saúde, sobretudo na vertente que compreende a saúde como uma parte do desenvolvimento integral do ser humano.

Bursztyn e Ribeiro23 identificam na abordagem participativa que vem se estabelecendo nos últimos anos uma postura colaborativa (engajamento dos interessados que partilham decisões e controle do projeto), em contraposição à tradicional postura de especialistas externos (os interessados valorizados como informantes, com as decisões e o controle permanecendo com o grupo técnico). Apesar do avanço significativo trazido pela postura colaborativa, estes autores chamam a atenção que esta perspectiva não pode ser confundida e nem substitui a formulação de Paulo Freire sobre a abordagem participativa na pesquisa e prática de planejamento e gestão de programas sociais. Já que Freire se focaliza no caráter estrutural das relações de poder e dominação no interior da sociedade.

Há de considerar que o recurso à abordagem participativa continua dizendo respeito, de modo quase que exclusivo, às pesquisas motivadas por questionamentos advindos da experiência e do referencial teórico de avaliadores externos. Dois fatos, no entanto, tornam necessários incluir a avaliação como preocupação cotidiana da Estratégia Saúde da Família, destacando o sentido prático de mediação de pactos: a) o compromisso dessa estratégia com a participação social para identificar as necessidades, programar e avaliar as ações propostas com base na realidade local, privilegiando o monitoramento das atividades de rotina que estaria vinculado aos processos de planejamento e decisão;6 b) a Política Nacional de Avaliação da Atenção Básica em Saúde que visa melhorar a qualidade da atenção neste nível do sistema de saúde. 1

A prática avaliativa constituída como processo de negociação coloca em evidência a questão da "vontade" enquanto decisão, deliberação, mostrando a importância de aproximar-se aos atos de natureza política para conhecer como se realizam as relações de poder, distribuem-se as responsabilidades dos envolvidos na avaliação e o modo pelo qual participam das decisões que lhes dizem respeito enquanto cidadãos. ${ }^{14}$ Uma análise crítica denota que a participação social não traduz necessariamente uma perspectiva ética. Alguns autores destacam os elementos típicos de controle sobre a sociedade e a possibilidade da falta de sintonia entre as percepções da população local e dos mediadores (técnicos e especialistas). ${ }^{24}$

Convém, portanto, interrogar-se no que consiste o "interesse público" que serve para justificar algum tipo de decisão, já que a formatação jurídico-institucional das instâncias oficiais de participação, como os conselhos de saúde, pode originar uma representação tendenciosa e manipulada. ${ }^{24}$ Supõe-se que os representantes conheçam os interesses, opiniões e direitos dos representados, expressando-os e defendendo-os. Porém, um representante ou uma institui- 
ção que não reconhece a pluralidade de características da população nem a diversidade de elementos que a constituem, pode ser quem define qual é o interesse dessa população, constituindo e expressando a "vontade comum". 3,5

Thompson 25 chama a atenção sobre a dependência entre a capacidade de agir em busca de alcançar objetivos e interesses e a posição do indivíduo ou grupo dentro de um campo de interação ou instituição. O que permite falar de indivíduos ou grupos "dominantes" e "subordinados", bem como de indivíduos ou grupos que, tendo acesso parcial a recursos, ocupam uma posição intermediária em um campo ou instituição. Para este autor, os casos de dominação têm particular importância quando suas características estruturais se repetem de um contexto a outro.

É pertinente lembrar as características estruturais das variadas formas de subordinação conformadas nos distintos contextos constituídos pelas equipes de saúde da família e as suas repercussões sobre as condições de uso da linguagem na avaliação. Por exemplo, entre outras, as relações de subordinação do tipo pessoa que demanda para satisfazer uma necessidade de saúde e profissional que realiza o atendimento, particularmente quando se trata do médico, que tem influência nas decisões técnicas. Também do tipo de funcionário que reivindica melhores condições de trabalho e instituição com a qual mantém um vínculo empregatício, que tem influência nas decisões políticas. Ademais, do tipo decorrente da desigualdade de valor atribuído aos distintos trabalhos na equipe, que tem influência sobre as decisões técnicas, éticas e políticas relacionadas ao cuidado.

Nessas situações, a possibilidade de universalização dos interesses, que está sempre presente na negociação, pode se concretizar pelo reconhecimento da autoridade. Já que os efeitos produzidos mediante o uso da linguagem dar-se-iam, principalmente, pelo fato de falar, isto é, pelos potenciais de ameaça mobilizados nas relações de poder configuradas no contexto em que a avaliação está sendo realizada. ${ }^{18,19}$ Essa interdição da intersubjetividade de escolhas e decisões faz com que os compromissos pactuados não traduzam o convencimento quanto à interpretação de necessidades e propostas de ação, fortalecendo a ideia de que a instituição deva ter necessariamente uma natureza constrangedora e repressiva.

No entanto, é fundamental destacar a importância das instituições como mediadoras na avaliação em saúde, já que é por meio do conjunto de medidas tomadas pelas pessoas e pelas institui- ções que se pode alcançar (ou não) a realização de fins individuais e coletivos. ${ }^{18,19,22}$ Todavia, uma perspectiva crítica acerca dessa mediação requer que seja explicitado se a decisão sobre a melhor forma de agir pressupõe o reconhecimento de pretensões de validade problemáticas, para que os acordos institucionais que servem aos interesses de alguns indivíduos não venham a ser apresentados como servindo aos interesses de todos. Em uma situação ideal, a prática comunicativa asseguraria a cada um o seu direito no que diz respeito ao movimento livre de temas e contribuições, informações e argumentos.

Certamente que a adaptação de gestores, profissionais de saúde e usuários às ações que se apoiam em uma racionalidade meio-fins, reforça a unilateralidade no uso da linguagem. Torna excepcional a "ação sensata", referida ao caráter necessariamente intersubjetivo da decisão. 26 Aspecto que cria dificuldades para o estabelecimento de vínculos de cooperação entre os interessados e inibe o potencial formativo da avaliação na Estratégia Saúde da Família. No dia a dia dessa estratégia constitui-se como uma tarefa primordial a formação de novos sistemas de valores relativos à avaliação continuada - para superar as concepções tradicionais arraigadas sobre o caráter burocrático dos sistemas de informações em saúde - e ao processo avaliativo como construção compartilhada de soluções, com base na compreensão dos significados e pressupostos dos envolvidos. Gadamer17 afirma que quanto mais racionais as formas de organização da vida (e do trabalho), menos a capacidade de julgamento é praticada e ensinada.

\section{Considerações finais}

O processo de aprendizagem individual, organizacional e social mediante o qual o valor atribuído é construção de um coletivo, confere legitimidade aos resultados da avaliação, contribuindo de forma mais efetiva para correção de rumos. Evidencia, portanto, um poder transformador que não se restringe à competência do saber-fazer, mas abrange também a expressão da multiplicidade de perspectivas interpretativas e de vivências. As implicações conceituais e práticas desse processo reconstrutivo remetem, simultaneamente, ao sentido formativo de aprimoramento das capacidades humanas, do ponto de vista gadameriano, ${ }^{4}$ e ao sentido de melhoria do programa contemplado no conceito de avaliação formativa. 27 Ambos os sentidos se revelam produtores de possibilidades novas no pensar e fazer dos implicados na prática avaliativa.

Este caráter processual e reconstruído da avalia- 
ção torna-se ainda mais fecundo quando se estabelece o diálogo entre a concepção, a execução e a avaliação de projetos e programas. De modo que o planejamento possa desempenhar o papel pretendido por Onocko 28 de mediador entre uma racionalidade crítica e a necessária instrumentalidade operativa. A argumentação desempenha um papel importante nesses processos de aprendizagem, já que as relações que uma pessoa, ou um grupo social, estabelece entre a razão (faculdade de avaliar e emitir juízos) e o mundo, por meio das necessidades, dos interesses e da ação, continuam sempre contingentes se não são acrescidas da habilidade de aprender dos seus erros, da refutação de pressupostos e do insucesso das suas intervenções. ${ }^{29}$

$\mathrm{Na}$ aprendizagem individual e coletiva de habilidades novas de interação e reflexão está implícita a necessidade de lidar com os diferentes grupos de interesses que possuem níveis diferenciados de poder e de controle sobre os recursos. O processo decisório compartilhado é uma rede de relações sempre tensas, na qual, constantemente, são vivenciados os avanços, os recuos, as revoltas e as alianças, tornando indispensável o questionamento do que é dito e da própria situação de uso da linguagem. 3,14,19,26 As mediações operadas trazem implícitas à noção de síntese do heterogêneo, a ideia de concordância discordante. 19 À gestão cabe a responsabilidade de colocar como um imperativo ético a transição de uma prática monológica para o diálogo.

É delicada e difícil a transição para o diálogo e a argumentação que, evidenciando os elementos mais estratégicos para aferir os sucessos e os fracassos da prática cotidiana, requer a força esclarecedora da

\section{Referências}

1. Brasil. Ministério da Saúde. Secretaria de Atenção à Saúde. Departamento de Atenção Básica. Coordenação de Acompanhamento e Avaliação. Avaliação na atenção básica em saúde: caminhos da institucionalização. Brasília, DF; 2005. 36 p.

2. Feliciano KVO. A relação entre o avaliador e o objeto avaliado. Rev Bras Saúde Matern Infant. 2005; 5 (Supl.1): S583-S592.

3. Habermas J. Teoria de la acción comunicativa. Tomo I. 2 ed. Madrid (España): Taurus; 1988.

4. Gadamer HG. Verdade e método: traços fundamentais de uma hermenêutica filosófica. 2 ed. Petrópolis: Vozes; 1998.

5. Ricoeur P. Interpretação e ideologias. 4 ed. Rio de Janeiro: Francisco Alves; 1990.

6. Brasil. Ministério da Saúde. Secretaria de Políticas de Saúde. Departamento de Atenção Básica. A implantação da unidade de saúde da família. Cadernos de atenção básica: programa de saúde da família. Caderno 1. Brasília, DF; reflexão e da auto-reflexão e a capacidade de privilegiar uma comunicação não-coagida. 4,15 A liberdade para posicionar-se permite a cada um colocar as suas ideias e intuições como aporte pessoal ao crescimento coletivo, pondo em jogo o interesse pela emancipação. É desta perspectiva que a comunicação é aqui tomada, como um conceito cuja definição completa só se realiza na medida em que os seus possíveis e variados usos vão se instituindo, por meio da relação com o outro, do diálogo e de ações. $3,4,14$

Para finalizar, cabe atentar-se que o fortalecimento da rede de negociações para a construção de mudanças passa, necessariamente, pelo estabelecimento de pactos que favoreçam o desenvolvimento e a sustentabilidade do processo avaliativo na Estratégia Saúde da Família. Estudo de implantação da Política Nacional de Avaliação da Atenção Básica em Saúde evidencia a premência dessa tarefa. Segundo Felisberto et al.,27 sobretudo desde 2003 até meados de 2005, duas características foram marcantes na atuação do Ministério da Saúde como indutor da integração do monitoramento e da pesquisa avaliativa à rede básica de saúde: o desenvolvimento da capacidade técnica e o foco no fortalecimento das Secretarias Estaduais de Saúde. Também avançaram os processos de negociação envolvendo as três esferas de gestão que resultaram no pacto de indicadores da atenção básica. O único dispositivo com grau de implantação insuficiente foi o Sistema de Informação da Atenção Básica (SIAB). As três esferas de gestão reconhecem a incipiência das práticas de monitoramento e avaliação na atenção básica.
2000.58 p

7. Brasil. Ministério da Saúde. Secretaria de Atenção à Saúde. Departamento de Atenção Básica. Política Nacional de Atenção Básica. 4 ed. Brasília, DF; 2007. [acesso em 17 set 2009]. Disponível em http://dtr2004.saude.gov.br/dab/ publicacoes.php.

8. Organização Mundial de Saúde. Carta de Ottawa, 1986 [aprovada na I Conferência Internacional sobre Promoção da Saúde]. [acesso em 24 abr 2008]. Disponível em http://www.saude.gov.br/portal.arquivos/pdf/05.pdf.

9. Carvalho MCB. Avaliação participativa: uma escolha metodológica. In: Rico EM, org. Avaliação de políticas sociais: uma questão em debate. 3 ed. São Paulo: Cortez; 2001. p. 87-94.

10. Minayo MCS. Pesquisa avaliativa por triangulação de métodos. In: Bosi MLM, Mercado FJ. orgs. Avaliação qualitativa de programas de saúde: enfoques emergentes. Petrópolis: Vozes; 2006. p. 163-90. 
11. Bodstein RCA. O debate sobre avaliação das práticas e estratégias em promoção da saúde. B. Téc. Senac: a R. Educ. Prof. 2009; 35 (2): 6-15. Disponível em: http://www.senac.br/BTS/352/artigo-01.pdf

12. Furtado JP. Um método construtivista para a avaliação em saúde. Ciênc Saúde Coletiva. 2001; 6: 165-81.

13. Guba EG, Lincoln YS. Guidelines and checklist for constructivist (a.k.a. fourth generation) evaluation. [acesso em 20 mai 2005]. Disponível em: http://geocities.com/HotSprings/Villa/4308/avafis.htm?

14. Marcondes D. Filosofia, linguagem e comunicação. 3 ed Petrópolis: Vozes; 2000.

15. Habermas J. Técnica e ciência como 'ideologia'. Lisboa (Portugal): Edições 70; 2001.

16. Gadamer HG. A razão na época da ciência. Rio de Janeiro: Ed. Tempo Brasileiro; 1983.

17. Gadamer HG. O caráter oculto da saúde. Petrópolis: Vozes 2006

18. Habermas J. Direito e democracia: entre facticidade e validade. V. 1. Rio de Janeiro: Tempo Brasileiro; 1997.

19. Ricoeur P. O si-mesmo como um outro. Campinas: Papirus; 1991.

20. Mattos RA. Os sentidos da integralidade: algumas reflexões acerca de valores que merecem ser definidos. In: Pinheiro R, Mattos RA, orgs. Os sentidos da integralidade na atenção e no cuidado à saúde. Rio de Janeiro: Universidade Estadual do Rio de Janeiro, Instituto de Medicina Social, Associação Brasileira de Pós-Graduação em Saúde Coletiva; 2001. p. 39-64

Recebido em 26 de abril de 2010

Versão final apresentada em 18 de outubro de 2010

Aprovado em 20 de outubro de 2010
21. Ayres JR. Norma e formação: horizontes filosóficos para as práticas de avaliação no contexto da promoção da saúde. Ciên Saúde Coletiva. 2004; 9: 583-92.

22. Habermas J. A ética da discussão e a questão da verdade. São Paulo: Martins Fontes; 2004.

23. Campos GWS. Eixos de conformação do método. In: Um método para análise e co-gestão de coletivos: a constituição do sujeito, a produção de valor de uso e a democracia em instituições: o método da roda. São Paulo: Hucitec; 2000. p. 21-65.

24. Bursztyn I, Ribeiro JM. Avaliação participativa em programas de saúde: um modelo para o Programa de Saúde do Adolescente. Cad Saúde Pública. 2005; 21: 404-16.

25. Thompson JB. Ideologia e cultura moderna: teoria crítica na era dos meios de comunicação de massa. 8 ed. Petrópolis: Vozes; 2009.

26. Ricoeur P. Do texto a acção: ensaios de hermenêutica II. Portugal: Editora Diagonal; 1989. 407 p.

27. Felisberto E, Freese E, Alves CKA, Bezerra LCA, Samico I. Política de monitoramento e avaliação da atenção básica no Brasil de 2003 a 2006: contextualizando a sua implantação e efeito. Rev Bras Saúde Matern Infant. 2009; 9: 33957.

28. Onocko Campos R. O planejamento no labirinto: uma viagem hermenêutica. São Paulo: Hucitec; 2003.

29. Habermas J. Teoría de la acción comunicativa: complementos y estudios previos. 3 ed. Madrid: Ed. Cátedra; 1997. 